\title{
Avaliação da internacionalização da educação superior: proposição de indicadores e mapeamento de processos
}

Guilherme Krause Alves Bacharel em Administração. Universidade Federal de Santa Catarina (UFSC) - Brasil. guilhermealv@gmail.com

\section{RESUMO}

O trabalho trata da internacionalização da educação e tem por objetivos discutir indicadores de avaliação e mapear o processo de formalização de acordos de cooperação internacional realizados na Universidade Federal de Santa Catarina (UFSC). Para tal, foi construído o quadro histórico da internacionalização da educação superior, contextualizada a internacionalização no Brasil e quanto à conjuntura deste processo no âmbito da instituição. $A$ partir do modelo proposto por Rudzki (1998), o processo de formalização de acordos de cooperação internacional da instituição foi mapeado e transposto para um fluxograma utilizando-se técnicas de business process management (BPM) e notação business process modeling notation (BPMN). Apesar da necessidade de estabelecer indicadores e parâmetros de avaliação, observou-se que os processos de internacionalização estão formalizados e atendem ao proposto por Rudzki (1998) até o terceiro estágio de seu modelo.

Palavras-chave: Internacionalização. Gestão de processos. Educação superior.

\section{Evaluation of internationalization of higher education: indicators proposition and process mapping}

\begin{abstract}
The research deals with the internationalization of higher education and aims to discuss evaluation indicators and map the process of formalizing international cooperation agreements signed by the Federal University of Santa Catarina (UFSC). For this, the historical framework of the internationalization of higher education was constructed, contextualizing the internationalization in Brazil and the conjuncture of this process within the institution. From the model proposed by Rudzki (1998), the process of formalization of international cooperation agreements of the institution has been mapped and transposed to a flowchart using business process management (BPM) and business process modelling notation (BPMN). Despite the need to establish indicators and parameters of evaluation, it was observed that internationalization processes are formalized and meet the proposed by Rudzki (1998) to the third stage of his model.
\end{abstract}

Keywords: Internationalization. Process management. Higher education. 


\section{INTRODUÇÃO}

A internacionalização da educação superior ocorre desde a Idade Média (TEICHLER, 2003), mas foi a partir do final do século XX, com a assinatura da Declaração de Bolonha (UNIÃO EUROPEIA, 2015), e no começo do século XXI, chamado de "o século da globalização", que as instituições de educação superior perceberam sua importância nos desafios propostos para o novo milênio (UNESCO, 2003).

Stallivieri (2009) ressalta a importância da internacionalização para o desenvolvimento das instituições de educação superior. Segundo a autora, além desse processo beneficiar o crescimento pessoal e profissional dos estudantes, fortalece os cursos de graduação e colabora com o progresso do país.

A compreensão do processo possibilita uma reflexão do trabalho na forma como é realizado. Oliveira (2006, p. 13) explica que deve haver a "constante e evolutiva melhoria dos processos através do desenvolvimento e aplicação contínua da administração de processos, seja para otimizar os negócios, a estrutura organizacional ou os resultados da empresa".

Tendo em vista a relevância do assunto, o presente trabalho tem por objetivo demonstrar como se dá o processo de formalização de um acordo de cooperação internacional entre uma instituição pública federal de ensino superior e outras instituições de ensino superior estrangeiras, mediante o mapeamento das tarefas desse processo.

Como objetivos específicos, buscou-se, com esse trabalho, discutir indicadores de avaliação e mapear o processo de formalização de acordos de cooperação internacional realizados na instituição estudada, a Universidade Federal de Santa Catarina (UFSC).

\section{INTERNACIONALIZAÇÃO DA EDUCAÇÃO SUPERIOR}

A internacionalização da educação superior, conforme a UNESCO (2003, p. 154), é entendida

como um conceito amplo, muito abrangente, que pode envolver a cooperação internacional, mas se refere também a mudanças que ocorrem dentro de uma determinada instituição, através de iniciativas políticas e de caráter específico.

Gacel e Ávila (2008) afirmam que a internacionalização evidencia uma resposta construída pelos atores universitários para se integrar à globalização de maneira proveitosa, eliminando as influências negativas da própria globalização. Ortiz (2004) diz que, nos Estados Unidos, esse movimento se intensificou com a percepção de que existe uma necessidade dos estudantes se adaptarem à economia global, em especial os estudantes de negócios. Pelo seu caráter multidisciplinar, a educação empresarial parece ter maior disposição para lidar com as questões internacionais, as quais extrapolam as barreiras das disciplinas acadêmicas, sendo meios complementares para a formação destes profissionais.

Tradicionalmente, a universidade teve por norma a internacionalização da pesquisa, considerando seu caráter de produtora de conhecimento. Quanto ao ensino, que costuma ter um maior controle por parte do estado, nem sempre possui a autonomia necessária para promover, de fato, a internacionalização (MOROSINI, 2006).

Já para Knight (2015, p. 2), a internacionalização da educação superior é o processo de "integração das dimensões internacional, intercultural ou global para atingir as metas, funções e entrega de educação". A autora explica que esta internacionalização não deve ser um fim em si mesmo, mas um "meio para melhorar ou alcançar os objetivos acadêmicos da instituição ou as metas socioculturais, econômicas ou políticas do país ou região".

Alguns benefícios que podem ser mutuamente obtidos pelas instituições que colaboram entre si são a "visão compartilhada dos resultados desejados", "ganhos compartilhados entre os parceiros institucionais" e "contribuição mútua e coprodução para agregar valor" (HUDZIK, 2015, p. 24, tradução nossa).

Knight (2013) explica que a grande dificuldade em encontrar uma definição para a internacionalização da educação superior é que esta definição deve ser genérica o suficiente para ser aplicada a muitos contextos diferentes, envolvendo distintos países, culturas e sistemas de ensino.

A internacionalização ocorre na Europa desde a Idade Média, onde era bem vista (TEICHLER, 2003). Naquela época, uma universidade não tinha necessariamente que estar estabelecida e organizada em um único lugar, bastava que houvesse um grupo de alunos e mestres residentes no mesmo local ou região para que ali se estabelecesse uma universitas, como era chamada nestes casos (BERLINCK, 2013).

$\mathrm{Na}$ Idade Média, era normal a mobilidade de estudantes e funcionários das universidades. Não só ocorria entre países, mas era desejável inclusive entre instituições da mesma região, entre regiões e entre culturas diversas. 
A mobilidade internacional, até próximo de 1800, não era considerada como distinta de qualquer outra modalidade de mobilidade espacial. A partir daquele período, com a criação do conceito de Estado-Nação, é que começou a haver esta distinção e, por consequência as limitações relacionadas (TEICHLER, 2003).

Já no final do século XX, em 1999, a Declaração de Bolonha representou um marco para o desenvolvimento da internacionalização da educação superior. Ela foi assinada inicialmente por 30 países europeus, e, no ano de 2015, possuía mais de quarenta e sete países participantes do Processo de Bolonha, que dela decorreu (UNIÃO EUROPEIA, 2015). A Declaração busca

introduzir um sistema de graus acadêmicos facilmente reconhecíveis e comparáveis, promover a mobilidade dos estudantes, dos professores e dos investigadores, assegurar a elevada qualidade da docência e incorporar a dimensão europeia no Ensino Superior (UNIÃO EUROPEIA, 2015).

A partir desse movimento, o século XXI passou a ser chamado como "o século da globalização". O termo busca descrever "o processo e o estado de interdependência que não é mais limitado ou suprimido pela distância" (UNESCO, 2003, p. 156).

Morosini (2006) relata que a internacionalização da educação superior passou por diversas fases de desenvolvimento: (i) dimensão internacional, em que é caracterizada por ser mais incidental do que organizada, presente no século XX; (ii) educação internacional, ocorrida principalmente nos Estados Unidos por razões políticas e de soberania nacional, no período entre a segunda guerra mundial e o final da guerra fria; e (iii) internacionalização da educação superior, processo ligado à globalização e à regionalização das sociedades, tendo seu início após o término da guerra fria.

Durante a Conferência Mundial Sobre Educação Superior +5 , evento realizado após a passagem de cinco anos da primeira Conferência de mesmo nome, foi apresentado que estava ocorrendo, à época, um abrangente processo de internacionalização da educação superior. Esse desenvolvimento estava indo além das tradicionais práticas de cooperação internacional, havendo um efeito de influência recíproca entre a globalização e a internacionalização. Nesse efeito, a internacionalização da educação superior é alimentada pela globalização. Dessa forma, a internacionalização é um meio que permite à educação superior enfrentar os desafios que propõe a globalização (UNESCO, 2003).

O mundo acadêmico impulsiona de forma contínua as estratégias tradicionais de internacionalização. No entanto, cada vez mais um número maior de instituições se dedica a novas práticas, exportando seus programas de educação superior por meio do recrutamento de estudantes estrangeiros, que pagam suas taxas, ou por meio do fornecimento de programas e cursos no exterior (UNESCO, 2003).

Ao longo da Conferência Mundial Sobre Educação Superior +5 foram expostos alguns fatores que incrementam o desenvolvimento da internacionalização da educação superior:

\footnotetext{
1) A percepção da importância do conhecimento (sua produção, difusão e aplicação) para o bem-estar econômico, social e cultural da sociedade em todo o mundo (a sociedade do conhecimento).

2) A integração em andamento e a aplicação das Tecnologias de Informação e Comunicação aos processos de aprendizado, ensino e pesquisa.

3) Novas pressões e demandas para que as instituições de educação superior preparem graduados, formandoos para toda a vida e para trabalhar em um contexto internacional.

4) A mobilidade cada vez mais fácil dos recursos humanos de alta qualificação, criando um mercado de trabalho internacional competitivo para os trabalhadores científicos e acadêmicos.

5) A redução ou estagnação do financiamento público da educação superior na maioria dos países, em todo o mundo, sem um declínio na demanda de acesso a essa educação.

6) $O$ aumento da pressão sobre as instituições de educação superior para que diversifiquem as fontes de financiamento, de modo a poder atender à sua demanda, o que em muitos aspectos alimenta a comercialização da educação, inclusive no nível internacional.

7) $O$ advento de novos supridores e inovadores no fornecimento da educação superior (em parte devido aos fatores acima relacionados), assim como em todo o sistema de produção do conhecimento (UNESCO, 2003, p. 160).
}

Hudzik (2015) diz que o surgimento de formas mais estratégicas e abrangentes de executar a internacionalização do ensino superior, a expansão da capacidade de pesquisa e a própria expansão do ensino superior são fatores para o aumento das colaborações interinstitucionais e transfronteiriças. Hagenmeier (2015) complementa afirmando que existe uma necessidade de que as universidades formem profissionais que possam exercer as suas profissões em diferentes contextos culturais e de desenvolvimento, e ainda se tornem cidadãos responsáveis e globalmente competentes.

Mais recentemente, três modelos de internacionalização das universidades têm sido propostos: (i) clássico, onde a instituição desenvolve atividades e parcerias múltiplas, tanto localmente quanto no exterior, envolvendo um espectro intercultural e internacional amplo de iniciativas acadêmicas, de pesquisa, serviços e gestão; (ii) modelo 
satélite, refere-se às instituições que possuem centros de pesquisa e escritórios fora do seu país de origem; e (iii) o modelo mais recente, onde dois ou mais parceiros internacionais fundam e desenvolvem em conjunto uma instituição nova e independente. Os modelos não se excluem mutuamente, e nem se considera um deles como ideal, mas a categorização auxilia no entendimento da forma como essas instituições se relacionam quanto à internacionalização e à cooperação internacional (KNIGHT, 2015).

De Wit (2015) ressalta que a parceria entre as instituições é o elemento essencial para o sucesso do empreendimento. $\mathrm{O}$ autor destaca que ela é a base para a construção da cooperação internacional, e apresenta quais as tendências que têm observado no que diz respeito à essas parcerias:

\footnotetext{
a) De bilateral para multilateral, trabalhando mais nas redes do que entre duas instituições;

b) De parcerias mais focadas no número de intercâmbios para relações de qualidade, onde o conteúdo e os resultados são mais relevantes;

c) De relações ad hoc e parcerias marginais para relações mais estratégicas e centrais; de transacional para transformacional (SUTTON apud DE WIT, 2005, p. 95, tradução nossa);

d) De parcerias com um único propósito para parcerias com múltiplos propósitos, em que várias atividades, incluindo a educação, pesquisa e benchmarking, estão ocorrendo;

e) De um tipo cooperativo para um tipo de relacionamento mais competitivo, em que os parceiros trabalham juntos e competem com os outros que não fazem parte da relação;

f) De parcerias de ensino superior para parcerias que incluem outras partes interessadas, tais como governos locais, o setor privado e as ONGs;

g) Construir parcerias educacionais em programas conjuntos, diplomação conjunta e dupla diplomação (DE WIT, 2005, p. 95, tradução nossa).
}

Silva (2007) apresenta que a cooperação internacional é a melhor forma para alcançar objetivos comuns no mundo globalizado, pois abre janelas de oportunidade para países em desenvolvimento. Os benefícios da cooperação são: compartilhamento de custos, acesso à experiência, tecnologia e instalações. A cooperação pode também ocorrer para estreitar relações políticas, exercer influência sobre parceiros e demonstrar liderança. No entanto, há o risco de perder a liberdade de ação, aumento da complexidade gerencial e são citadas como desvantagens: (i) transferência tecnológica de maneira indesejada, (ii) ajuda involuntária em criar ou fortalecer futuros competidores e (iii) riscos políticos caso a cooperação falhe.

Outra discussão é a mercantilização da educação onde a internacionalização é vista muitas vezes como um meio para tal. Knight (2013) afirma que este é o risco de número um, identificado em pesquisa realizada junto à Associação Internacional de Universidades no ano de 2005. Jooste (2015) explica que algumas universidades buscam aumentar a sua presença em outros países, principalmente nas do hemisfério sul do planeta, tal como o fazem empresas multinacionais, objetivando o crescimento de sua presença e, por meio disto, do seu lucro. O autor questiona inclusive, de forma irônica, se não seria a Organização Mundial do Comércio a entidade responsável por regular as fusões, aquisições e parcerias entre universidades de diferentes países.

Em tal linha de raciocínio, o autor propõe uma relação de parceria horizontal entre as instituições, que incluiria "a existência de prévio conhecimento uns dos outros para estabelecer expectativas realistas", o "compartilhamento genuíno da experiência uns dos outros", e "a aplicação do conhecimento um do outro, ao invés de transferência one-way" (JOOSTE, 2015, p. 18-19 tradução nossa). Duffield, Olson e Kerzman (2012) dizem que a presença de objetivos comuns e compartilhados, além de comunicação, comprometimento, confiança e benefícios mútuos são fatores determinantes para o sucesso de parcerias de longo prazo.

Os termos a serem considerados em acordos de cooperação devem levar em conta fatores comerciais, econômicos e políticos. Mas é necessário tomar cuidado para não confundir o plano de internacionalização das universidades com marketing internacional. O plano de internacionalização deve englobar muitos outros aspectos para além da mera atração de estudantes para determinada universidade (KNIGHT, 2013).

Leite e Genro (2012) afirmam que o modelo de internacionalização que ocorre atualmente, baseado principalmente no Processo de Bolonha, é uma forma de dominação por parte dos países desenvolvidos sobre os mais pobres, também chamado pelas autoras de "imperialismo benevolente". Os objetivos dessa dominação seriam, na opinião das autoras, a exportação da educação superior e a disseminação de valores e conhecimentos; direcionando, dessa forma, as políticas educacionais conforme os interesses dos países dominantes.

Beelen (2015) crítica o excessivo foco nos meios, em detrimento dos objetivos a serem alcançados, desconsiderando indicadores de qualidade. Existem instituições que somente aparentam seguir princípios morais elevados, mas não os colocam em prática. O autor explica que a falta de clareza dos conceitos relacionados à internacionalização da educação superior é um obstáculo para a sua implementação. De modo geral, a internacionalização é considerada simplesmente como a mobilidade acadêmica, quando o conceito engloba um significado maior. Nesse caso, a internacionalização doméstica, ou seja, a inclusão de dimensões relacionadas ao 
currículo, não seria considerada. Também alerta para a falta de capacitação do corpo docente, especialmente no que diz respeito à proficiência em língua estrangeira e mobilidade.

Morosini (2011) defende que tanto a cooperação internacional tradicional quanto a horizontal são importantes. A internacionalização sul-norte é relevante considerando o conhecimento acumulado pelas nações mais desenvolvidas e suas universidades, enquanto a cooperação horizontal, ou sul-sul, é importante por ajudar os países em desenvolvimento a fortalecerem-se como bloco.

Fica clara a necessidade de adequação das instituições de nível superior aos novos desafios e demandas. Jooste (2015) afirma que a cooperação entre as instituições deve contribuir para a sociedade como um todo. Tais afirmações são corroboradas por Stallivieri (2009, p. 164), quando afirma que é

evidente a necessidade e a relevância de um programa de mobilidade acadêmica internacional para o desenvolvimento de um país, para uma instituição, para o fortalecimento dos programas de graduação e, em especial, para o crescimento pessoal e profissional dos estudantes.

Rudzki (1998) apresenta um modelo que sintetiza o processo de internacionalização da educação superior. Para o autor, há diversas etapas no processo de internacionalização. A primeira é a avaliação do contexto, tanto no sentido político, verificando se é do interesse da instituição e se existe o apoio nacional necessário para seguir com o processo, quanto no sentido de existir o apoio necessário no sentido financeiro, por meio de bolsas ou outros tipos de fomento. Desse modo, evita-se o empenho em uma demanda que acaba por se mostrar inviável.

A segunda etapa é a abordagem. Nesse momento, são verificados aspectos como o histórico e a cultura das instituições, bem como suas prioridades, missão e percepção com relação aos propósitos e benefícios da internacionalização (RUDZKI, 1998).

Na terceira etapa, Rudzki (1998) explica que serão verificadas as razões para seguir o processo de internacionalização, como as demandas políticas e da sociedade. O autor cita como exemplo razões políticas e econômicas para adoção da internacionalização do ensino superior.

Na etapa chamada Ações/Dimensões/Atividades é onde ocorrem de fato as mudanças na instituição. $\mathrm{O}$ autor dividiu estas mudanças em quatro dimensões: Mudança Organizacional, Inovação Curricular, Desenvolvimento da Equipe e Mobilidade Estudantil (RUDZKI, 1998).

A etapa seguinte, segundo Rudzki (1998), diz respeito à fase de Monitoramento e Revisão Periódica. O autor explica que a internacionalização necessita de constante monitoramento das ações, por meio de acompanhamento e feedback, de modo a verificar se o processo está correndo da forma adequada. Nesse estágio também deve ser realizada a revisão das práticas, se necessário, no que é descrito por Rudzki (1998, p. 226, tradução nossa) como um "modelo de melhoria contínua da qualidade", mediante a avaliação do processo.

Por fim, no último estágio, são realizadas as mudanças necessárias ao processo, conforme as possíveis falhas verificadas na etapa anterior, garantindo dessa forma um ciclo de adaptação do ambiente externo e interno da instituição, e por consequência a continuidade do processo (RUDZKI, 1998). O modelo, com suas etapas, está apresentado na Figura 1:

Figura 1 - Modelo de internacionalização

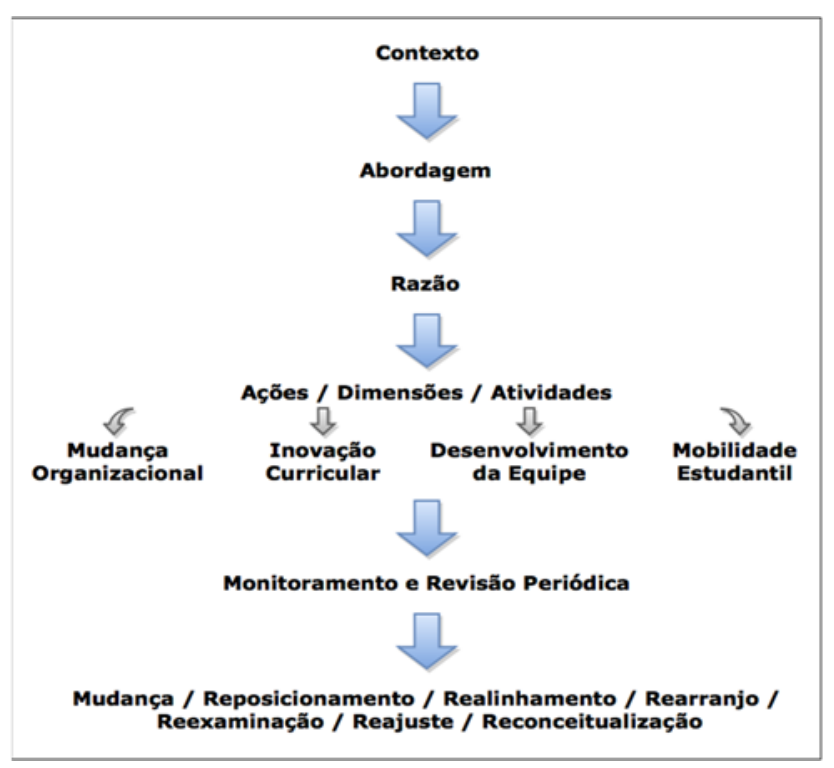

Fonte: Adaptado de Rudzki (1998, p. 220, tradução nossa). 


\section{INTERNACIONALIZAÇÃO NO BRASIL}

No Brasil, a internacionalização da Educação Superior tem ocorrido mais recentemente e tem provocado um debate político sobre soberania nacional. No entanto, pouco se tem explorado a respeito do ponto de vista organizacional e dos possíveis ganhos resultantes de um melhor desempenho das instituições para a sociedade, 0 setor produtivo, os estudantes e os trabalhadores do setor (SOUZA; FLEURY, 2009).

Dal-Soto et al., (2013, p. 14) dizem que

O ambiente acadêmico em geral, no Brasil, tem vivido um choque de realidade internacional a partir do reconhecimento da pouca tradição do Ensino Superior brasileiro e da defasagem nacional em termos de internacionalização do setor, especialmente quando comparado aos principais centros acadêmicos do mundo.

Stallivieri (2009) acrescenta que, com relação às universidades localizadas em países lusófonos, como no caso das instituições brasileiras, é imprescindível que sejam envolvidos na questão da internacionalização docentes que possuam proficiência ao menos em uma língua estrangeira, preferencialmente a língua de comunicação internacional ou língua franca que, neste momento, é o inglês, seguido do espanhol.

Dentro desse contexto, o ambiente acadêmico nacional tem sido desafiado pelas diversas possibilidades de interação com IES de outros países, tanto no sentido incoming quanto no outgoing. Várias IES, agências internacionais, a iniciativa privada, e o próprio governo federal vêm fomentando estas oportunidades. Um exemplo emblemático é o programa Ciência sem Fronteiras. "Esses movimentos orientam para o desenvolvimento de uma cultura de internacionalização no meio acadêmico, com reflexos na sociedade brasileira em geral" (DAL-SOTO et al., 2013, p. 14).

No Brasil, existem órgãos governamentais responsáveis pelo fomento e incentivo da internacionalização da Educação Superior. A Coordenação de Aperfeiçoamento de Pessoal de Nível Superior (CAPES) é uma fundação vinculada ao Ministério da Educação (MEC) e possui por objetivo expandir e consolidar a pós-graduação stricto sensu (mestrado e doutorado) no Brasil através das seguintes linhas de ação:

a) Avaliação da pós-graduação stricto sensu;

b) Acesso e divulgação da produção científica;

c) Investimentos na formação de recursos de alto nível no país e exterior;

d) Promoção da cooperação científica internacional;

e) Indução e fomento da formação inicial e continuada de professores para a educação básica nos formatos presencial e a distância (CAPES, 2015).

$\mathrm{Na}$ Cooperação Internacional, o objetivo da CAPES é "desenvolver as atividades da pós-graduação brasileira no contexto mundial". Ela "busca apoiar os grupos de pesquisa brasileiros por meio do intercâmbio internacional, buscando a excelência da nossa pós-graduação". A CAPES faz isso mediante acordos bilaterais, "programas que fomentam projetos conjuntos de pesquisa entre grupos brasileiros e estrangeiros", fomentando missões de trabalho realizadas por professores, bolsas de estudo para alunos e uma parte para custeio da atividade dos projetos; e parcerias universitárias binacionais, em que o objetivo é incentivar o intercâmbio de aluno da graduação, pósgraduação e professores (CAPES, 2015).

Já o Conselho Nacional de Desenvolvimento Científico e Tecnológico (CNPq), agência do Ministério da Ciência, Tecnologia e Inovação (MCTI), possui como missão "Fomentar a Ciência, Tecnologia e Inovação e atuar na formulação de suas políticas, contribuindo para o avanço das fronteiras do conhecimento, o desenvolvimento sustentável e a soberania nacional" (CNPQ, 2015a).

O CNPq tem forte atuação na internacionalização da educação superior. Um dos programas mais proeminentes neste sentido é Ciência sem Fronteiras, que "busca promover a consolidação, expansão e internacionalização da ciência e tecnologia, da inovação e da competitividade brasileira por meio do intercâmbio e da mobilidade internacional". Ele é resultado de um esforço conjunto entre os Ministérios da Ciência, Tecnologia e Inovação (MCTI) e da Educação (MEC), por intermédio de suas instituições de fomento, CNPq e CAPES, e Secretarias de Ensino Superior e de Ensino Tecnológico do MEC (CNPQ, 2015b).

Outro programa relacionado é o de Cooperação Internacional, que visa "fortalecer e aperfeiçoar a colaboração internacional em C, T\&I [Ciência, Tecnologia e Inovação], mobilizando competências no Brasil e no exterior, contribuindo para a qualificação de pessoas e promovendo pesquisa, desenvolvimento e inovação". Este programa apoia a "mobilidade de pesquisadores no desenvolvimento conjunto de pesquisas, a capacitação em alto nível de recursos humanos, além de participação em organismos internacionais" (CNPQ, 2015a).

A Agência Brasileira de Cooperação $(A B C)$ também é um órgão responsável por incentivar a cooperação internacional, faz parte do Ministério das Relações Exteriores (MRE) e possui como atribuição "negociar, coordenar, 
implementar e acompanhar os programas e projetos brasileiros de cooperação técnica, executados com base nos acordos firmados pelo Brasil com outros países e organismos internacionais". A ABC segue as diretrizes definidas pelo Governo do Brasil, que se materializam por meio da política externa do Ministério das Relações Exteriores e das prioridades nacionais de desenvolvimento (ABC, 2015).

\section{AVALIAÇÃO E INDICADORES}

Ao tratar da expansão da educação superior no Brasil, ANDIFES (2012) colocou metas quantitativas no Plano Nacional de Educação (PNE) do período 2011/2020. Ao lado das metas quantitativas está a preocupação com reestruturações acadêmicas e curriculares que proporcionem maior mobilidade estudantil, trajetórias de formação flexíveis, redução das taxas de evasão, utilização adequada dos recursos humanos e materiais, bem como proporcionar aos estudantes formação multi e interdisciplinares, formação humanista e desenvolvimento do espírito crítico. As universidades, ao interagirem com suas congêneres de melhor qualidade, tem na internacionalização um dos norteadores do plano de expansão da educação brasileira.

Com relação a avaliação dos processos de internacionalização, o Fórum de Pró-Reitores de Extensão das Instituições de Ensino Superior Públicas Brasileiras (FORPROEX, 2013) coloca que a internacionalização universitária brasileira deve ser avaliada através de:

a) Estabelecimento de convênios guarda-chuva entre Ministérios da Educação e Chancelarias/Ministérios de Relações Internacionais;

b) Adesão oficial das instituições interessadas;

c) Abertura de editais para projetos específicos de intercâmbio, prevendo equipes, anuência das comunidades, objetivos, métodos e formas de avaliação;

d) Definição de contrapartidas financeiras e estruturais no termo de convênio;

e) Intercâmbio de equipes de acordo com os recursos disponibilizados;

f) Períodos de intercâmbio compatíveis com os objetivos do programa;

g) Compromisso de continuidade das ações das equipes;

h) Atenção detalhada com relação aos processos preparatórios (domínio da língua do país visitado, instrumentalização da equipe com relação à geografia, história, cultura e política e instrumentalização com relação aos pontos fortes, fracos e resultados obtidos e esperados das ações) (FORPROEX, 2013).

Ainda com relação aos indicadores, a Universidade de São Paulo (USP, 2009), ao definir uma política de internacionalização do ensino e pesquisa, estabeleceu como indicadores:

a) Convênios / parcerias / intercâmbios estudantis estabelecidos;

b) Visitas e/ou estágios no exterior;

c) Visitantes acolhidos;

d) Alunos envolvidos em programas de intercâmbio;

e) Captação de recursos para organização de eventos internacionais, intercâmbio acadêmico docente / estudantil e projetos que envolvam parcerias internacionais;

f) Bolsas de estudo para fins de intercâmbio acadêmico docente / estudantil;

g) Participações em eventos (com ou sem apresentação de trabalhos);

h) Trabalhos publicados em veículos internacionais;

i) Projetos de pesquisa conjuntos e financiamentos recebidos em projetos conjuntos.

Veiga (2012) propõe a construção de indicadores de avaliação da internacionalização em universidades portuguesas. Segundo a autora, os indicadores podem ser divididos em três grupos: ensino/aprendizagem, investigação e cooperação. O Quadro 1 apresenta os indicadores de cada grupo.

Quadro 1 - Indicadores de internacionalização

\begin{tabular}{|l|l|}
\hline \multirow{4}{*}{$\begin{array}{l}\text { Indicadores de } \\
\text { ensino/aprendizagem }\end{array}$} & $N^{\circ}$ de docentes outgoing $/ \mathrm{n}^{\circ}$ total de docentes \\
\cline { 2 - 2 } & $N^{\circ}$ de docentes incoming $/ \mathrm{n}^{\circ}$ total de docentes \\
\cline { 2 - 2 } & $N^{\circ}$ de estudantes outgoing/no total de estudantes \\
\cline { 2 - 2 } & $N^{\circ}$ de estudantes incoming $/ \mathrm{n}^{\circ}$ total de estudantes \\
\cline { 2 - 2 } & $\begin{array}{l}N^{\circ} \text { de funcionários não docentes outgoing } / \mathrm{n}^{\circ} \text { total de funcionários não } \\
\text { docentes }\end{array}$ \\
\hline
\end{tabular}




\begin{tabular}{|c|c|}
\hline & $\begin{array}{l}\text { No de funcionários não docentes incoming } / \mathrm{n}^{\circ} \text { total de funcionários não } \\
\text { docentes }\end{array}$ \\
\hline & $\begin{array}{l}\text { Montante de fundos atribuídos para mobilidade no ano em análise/orçamento } \\
\text { total da IES no mesmo ano. }\end{array}$ \\
\hline & $\begin{array}{l}\text { No de funcionários afectos ao gabinete de mobilidade } / n^{\circ} \text { total de funcionários } \\
\text { não docentes }\end{array}$ \\
\hline & \% de cursos que contemplam pelo menos uma disciplina em inglês \\
\hline & $N^{\circ}$ de disciplinas lecionadas em inglês/nº de cursos \\
\hline & $\mathrm{N}^{\circ}$ de estrangeiros docentes $/ \mathrm{n}^{\circ}$ total de docentes \\
\hline & $\mathrm{N}^{\circ}$ de estudantes estrangeiros/ $\mathrm{n}^{\circ}$ total de estudantes \\
\hline & Sítio na internet em inglês \\
\hline & A IES tem em funcionamento o EILC (Erasmus Intensive Language Course) \\
\hline \multirow{7}{*}{$\begin{array}{l}\text { Indicadores de } \\
\text { investigação }\end{array}$} & $N^{\circ}$ de doutorados por IES internacionais/nº de doutorados \\
\hline & № de publicações em revistas científicas internacionais com afiliação nas IES \\
\hline & № de investigadores bolsistas em unidades de investigação da IES \\
\hline & $\mathrm{N}^{\circ}$ de patentes registradas internacionalmente \\
\hline & $N^{\circ}$ de reuniões científicas internacionais realizadas \\
\hline & № de projetos de investigação científica realizadas em consórcio com IES \\
\hline & $\mathrm{N}^{\circ}$ de projetos de investigação financiados internacionalmente $/ \mathrm{n}^{\circ}$ de projetos \\
\hline \multirow{4}{*}{$\begin{array}{l}\text { Investigadores de } \\
\text { cooperação }\end{array}$} & № de parceiros para mobilidade (Erasmus) \\
\hline & № de graduações conjuntas com IES internacionais \\
\hline & Participação na EUA (European University Association) \\
\hline & Participação na LERU (League of European Research University) \\
\hline
\end{tabular}

Fonte: adaptado de Veiga (2012, p. 52)

Com as métricas disponíveis, é possível estabelecer uma avaliação dos processos de internacionalização, embora esta requeira o estabelecimento de parâmetros que qualifiquem a gestão dos processos na IES. A discussão a este respeito ainda é incipiente.

\section{METODOLOGIA}

Para a execução da pesquisa, foi construído o quadro histórico da internacionalização da educação superior. Buscou-se contextualizar a internacionalização no Brasil e quais os órgãos responsáveis pelo incentivo à prática no país. Também foi tratada a conjuntura deste processo no âmbito da instituição estudada, qual o setor responsável, e quais são as suas atribuições.

A caracterização da pesquisa identifica-se como sendo um estudo de caso descritivo, uma vez que o assunto abordado não permite uma quantificação direta de todas as variáveis por meio de recursos estatísticos. O ambiente natural como fonte direta de dados, o pesquisador como instrumento fundamental e o caráter descritivo são características apontadas por Godoy (1995) para uma pesquisa qualitativa. Assim, buscou-se descrever como se dá o processo de formalização de acordos de cooperação internacional entre a Universidade Federal de Santa Catarina (UFSC) e instituições de educação superior de fora do Brasil, por meio de fluxogramas.

A coleta dos dados foi realizada a partir de documentos e relatórios disponibilizados pela instituição por solicitação do pesquisador, bem como informações acessíveis por meio do sítio da internet da UFSC, quando pertinentes ao assunto e agregassem conteúdo relevante ao estudo. Tais dados foram coletados no decorrer do primeiro semestre do ano de 2015.

A partir destes dados é realizada uma contraposição do modelo proposto por Rudzki (1998), buscando verificar se as etapas descritas no processo realizado na instituição estudada correspondem àquelas propostas pelo autor. Desta forma, a abordagem para a análise dos dados pode ser considerada como dedutiva, uma vez que, conforme explica Barral (2003, p. 76), "uma proposição teórica geral é aplicada a um caso particular". Vergara (1997) ainda afirma que os dados podem ser tratados de forma qualitativa e codificados de forma mais estruturada, possibilitando a análise.

Com base nas informações colhidas, o processo de formalização dos convênios foi mapeado e elaborado um fluxograma, a fim de facilitar a análise do processo como um todo. A coleta foi realizada por meio de consultas ao site da UFSC e, em especial, da Secretaria de Relações Internacionais (SINTER) da instituição. Os processos foram transpostos para um fluxograma utilizando-se técnicas de Business Process Management (BPM) e notação Business Process Modeling Notation (BPMN). BPM é uma forma de mapear fluxos de trabalho em organizações, enquanto BPMN é entendido como uma notação de fácil entendimento por todos os envolvidos no negócio (JULIATTO et al., 2012 ). 
Quanto às limitações do estudo, deverá ser considerado o escopo reduzido à organização em questão, que pode ter uma realidade diferente de outras. Além disso, é necessário ponderar o fato de que a UFSC passa ainda por um processo de sistematização das informações disponibilizadas. Assim, nem todas as informações podem estar disponíveis nas fontes consultadas. Por fim, a pesquisa contemplou a realidade de um período específico, a qual poderá mudar conforme ações ou redirecionamentos da gestão.

\section{A INTERNACIONALIZAÇÃO NA UFSC}

A Universidade Federal de Santa Catarina (UFSC) é uma autarquia de regime especial, vinculada ao Ministério da Educação, sendo uma instituição de ensino superior e pesquisa, com sede em Florianópolis, capital do Estado de Santa Catarina (UFSC, 2015a). O órgão responsável por conduzir e realizar estes acordos é a Secretaria de Relações Internacionais (SINTER), que

tem por objetivos primordiais promover a interação com organismos e instituições internacionais de Ensino Superior, apoiar e implementar acordos de cooperação técnica, científica e cultural, bem como viabilizar o intercâmbio de estudantes, professores e servidores técnico-administrativos (UFSC, 2015b).

A instituição possui uma política ativa de internacionalização, tendo viabilizado o intercâmbio no exterior de aproximadamente 1.400 estudantes no segundo semestre de 2014, recebendo 450 estudantes estrangeiros. A instituição participa de diversos programas de mobilidade acadêmica internacional como o Ciência sem Fronteiras, Erasmus, Escala AUGM, PEC-G e PEC-PG, Pró-Haiti, USAC, entre outros (UFSC, 2015b).

Até o ano de 2014, a Instituição mantinha 403 convênios firmados com Instituições localizadas em mais de 50 países. Por meio desses acordos de cooperação, a política de internacionalização da UFSC busca promover excelência científica e tecnológica do país e proporcionar solidariedade entre os povos, com ações articuladas de modo a obter consonância com os objetivos do ensino de graduação e pós-graduação, da pesquisa e da extensão, elevando a qualidade acadêmica da instituição. O Gráfico 1 apresenta a distribuição desses convênios por continente (UFSC, 2015b).

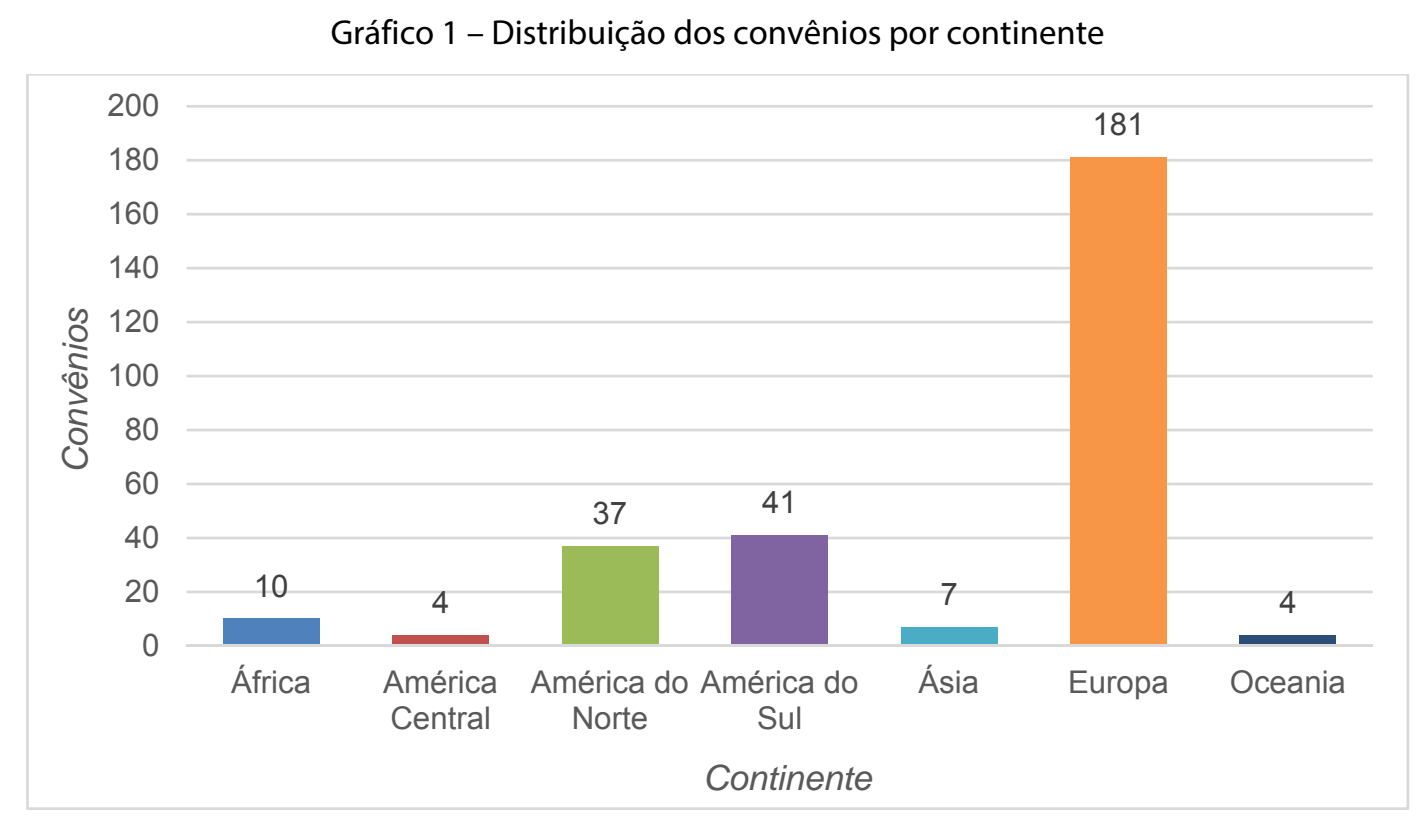

Fonte: Elaborado pelos autores a partir de UFSC (2015b)

Observa-se na distribuição dos convênios por continente, o predomínio de acordos firmados com instituições europeias, que representam mais da metade do total. Ao contrário, os continentes da América Central e da Oceania são aqueles que menos possuíam convênios, ocupando posição intermediária os continentes da América do Norte e da América do Sul. Importante notar que, apesar da disparidade dos números entre os continentes, todos possuíam instituições com acordos firmados com a UFSC à época da pesquisa. 


\section{MAPEAMENTO DO PROCESSO DE FORMALIZAÇÃO DE ACORDOS DE COOPERAÇÃO INTERNACIONAL}

Segundo UFSC (2015b), são propostos dois modelos para formalização de convênios entre a UFSC e alguma instituição de Ensino Superior estrangeira: quando o acordo é proposto localmente, mediante solicitação de algum docente da própria UFSC, ou quando este é proposto por algum representante da instituição estrangeira.

O primeiro modelo é transcrito da seguinte forma:

1) Proponentes da UFSC devem submeter por e-mail (convenio.sinter@contato.ufsc.br) o Formulário de Solicitação contendo as justificativas circunstanciadas e a assinatura do setor de origem (chefe do departamento ou coordenador da pós-graduação), indicando, quando for o caso, a data de aprovação no respectivo colegiado. 2) O Coordenador de convênios internacionais da SINTER avaliará o mérito das propostas, de acordo com os critérios abaixo listados.

3) Após a aprovação de mérito, a SINTER se encarregará de negociar diretamente com a IE os termos do convênio. A duração desta negociação é variável e dependerá grandemente da agilidade do setor estrangeiro responsável.

4) Antes da coleta das assinaturas, por exigência da legislação brasileira, o documento deverá passar ainda por análise jurídica da Procuradoria Federal.

5) Após a coleta final de assinaturas, o proponente será comunicado e o convênio será divulgado na página da SINTER.

6) No caso de editais que exijam convênios ou acordos, os proponentes serão responsáveis pelo correto encaminhamento de sua proposta dentro dos prazos necessários. O mesmo é válido para alunos, professores e servidores interessados em intercâmbio.

7) Casos especiais serão considerados individualmente (UFSC, 2015b).

Já o segundo é transcrito da seguinte maneira:

1)Proponentes estrangeiros deverão, preferencialmente, submeter por e-mail (convenio.sinter@contato.ufsc.br) o Agreement Proposal Form preenchido, assinado e carimbado.

2) O Coordenador de convênios internacionais da SINTER avaliará o mérito das propostas, de acordo com os critérios abaixo listados.

3) Após a aprovação de mérito, a SINTER se encarregará de negociar diretamente com a IE os termos do convênio. A duração desta negociação é variável e dependerá grandemente da agilidade do setor estrangeiro responsável.

4) Antes da coleta das assinaturas, por exigência da legislação brasileira, o documento deverá passar ainda por análise jurídica da Procuradoria Federal.

5) Após a coleta final de assinaturas, o proponente será comunicado e o convênio será divulgado na página da SINTER.

6) Casos especiais serão considerados individualmente (UFSC, 2015b).

Os dois modelos são bastante semelhantes, diferenciando-se na primeira etapa, que distingue proponentes estrangeiros de proponentes da UFSC. Portanto, serão analisados de forma unificada. Esse processo, conforme já citado, foi transposto para um fluxograma utilizando-se técnicas de Business Process Management (BPM), e notação Business Process Modeling Notation (BPMN). BPM é uma "forma de mapear fluxos de trabalho em organizações", enquanto BPMN é entendido como uma "notação de fácil entendimento por todos os envolvidos no negócio" (JULIATTO et al., 2012, p. 4-5). O resultado desta transposição é apresentado na Figura 2. 
Figura 2 - Fluxograma de formalização de convênio com IES estrangeira

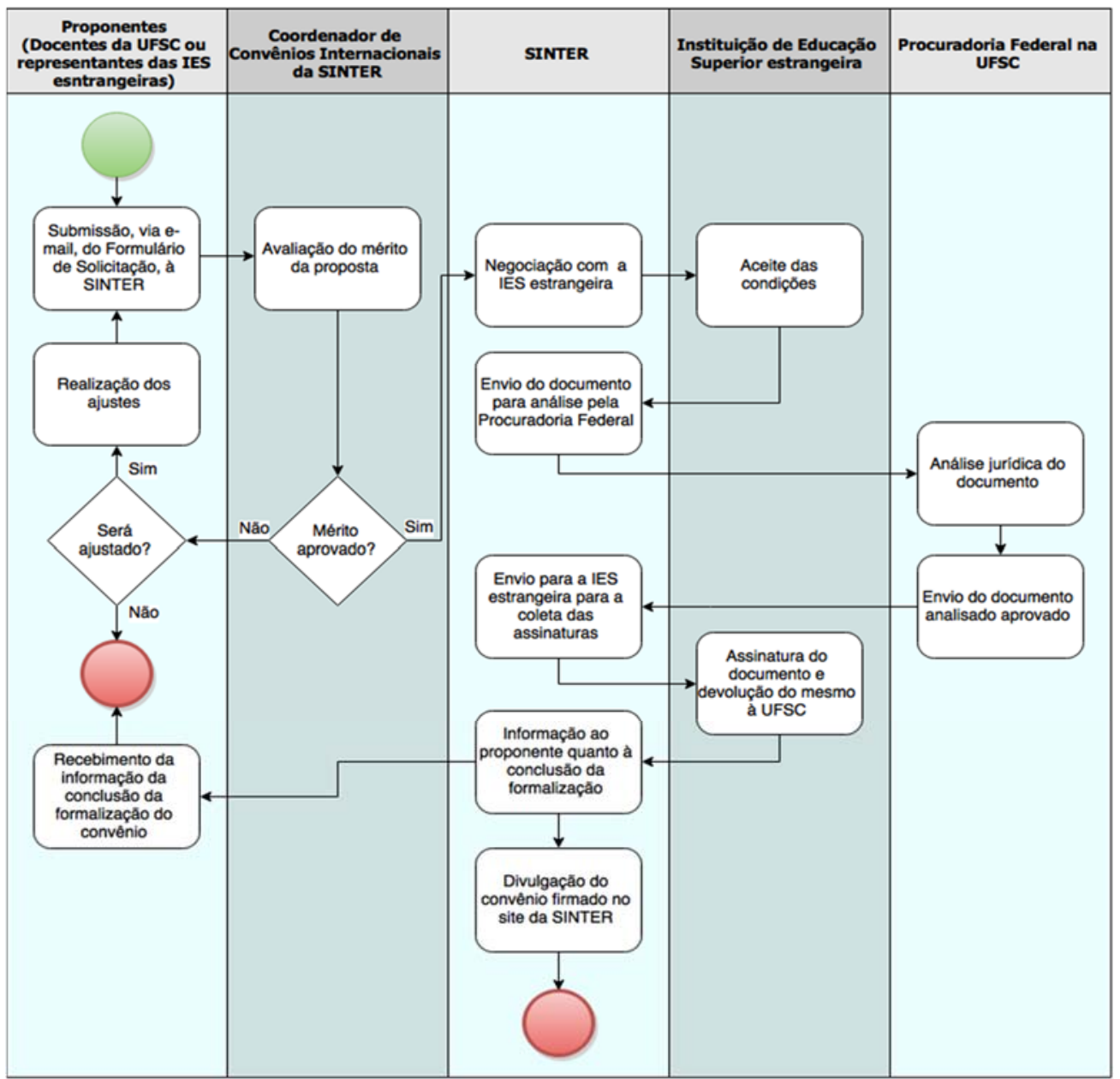

Fonte: Elaborado pelos autores a partir de UFSC (2015).

Conforme pode ser observado, a SINTER realiza uma análise das propostas enviadas, com a finalidade de certificar "se a mesma apresenta interesse institucional" e "se não contraria a política de Relações Internacionais da UFSC" (UFSC, 2015b). Nesta análise, são considerados os seguintes critérios:

1) Qualidade da instituição estrangeira (IE). Serão considerados aspectos como história, porte, estrutura, produção científica e estrutura de internacionalização da $\mathrm{IE}$, levando-se em conta os padrões acadêmicos particulares daquele país ou região.

2) Preenchimento de vazios geográficos e solidariedade internacional. A nossa política priorizará, através de uma postura proativa, convênios com IEs da América Central e do Sul, África, Ásia e Oceania, em países nos quais a UFSC ainda tenha representação incipiente ou inexistente, sem enfraquecer nem tampouco subestimar as excelentes relações com países da Europa e América do Norte.

3) Existência de ações concretas de cooperação (histórico, projetos acadêmicos, redes, pedidos de financiamento, etc.) que venham garantir a efetividade do convênio.

4) Reciprocidade de condições e termos do convênio.

5) Abrangência de áreas de conhecimento (que o convênio seja aberto a todos os departamentos) e de nível acadêmico (graduação e pós-graduação). Só realizaremos convênios específicos se houver razões que impeçam o convênio geral.

6) Caráter institucional. As propostas locais devem ter sido previamente aprovadas pelo setor correspondente à sua origem (departamento, centro de ensino, curso de graduação, PG etc.).

7) Comprometimento financeiro. A UFSC não aprovará convênios que prevejam compromisso financeiro de nossa instituição, a menos que haja aporte externo assegurado.

8) Isenção de taxas. Nossos convênios devem prever isenção mútua de quaisquer taxas.

9) Renovação. Nossos convênios não serão automaticamente renováveis.

10) Após aprovação do mérito, tratativas serão feitas preferencialmente com os escritórios de assuntos internacionais das IEs (UFSC, 2015b).

Em comparação ao modelo de Rudzki (1998) apresentado anteriormente, pode-se inferir que a SINTER executa o processo de internacionalização, com relação à formalização de seus convênios, de maneira muito semelhante àquela proposta pelo autor (1998) até o terceiro estágio de seu modelo. A avaliação do contexto, a abordagem e a verificação das razões para a formalização do convênio são claramente realizadas, conforme os dados colhidos. 
A existência de uma secretaria dedicada a tratar das ações de internacionalização na instituição demonstra um direcionamento à quarta etapa do modelo de Rudzki (1998), especialmente com relação às mudanças organizacionais, como a criação de setores administrativos específicos de apoio à mobilidade estudantil. Isto pode ser corroborado também pelo número de estudantes recebidos e enviados por intermédio de intercâmbio com instituições estrangeiras, evidenciando a mobilidade estudantil que está referenciada no quarto estágio proposto por Rudzki (1998). No entanto, a instituição estudada ainda está em processo de sistematização das informações sobre os investimentos no monitoramento e na avaliação dos resultados da cooperação, a exemplo do que é proposto por Rudzki (1998) nos demais estágios de seu modelo.

\section{CONCLUSÃO}

O presente trabalho abordou o processo de formalização de acordos de cooperação internacional realizados pela Secretaria de Relações Internacionais (SINTER) da Universidade Federal de Santa Catarina (UFSC).

Por meio da fundamentação teórica, foi possível verificar o quanto o tema da internacionalização é importante, e cada vez mais essencial para a obtenção de melhores resultados acadêmicos por parte das instituições de educação superior. Apesar disso, o assunto não é novo, visto que o processo ocorre desde a Idade Média.

Ensina Stallivieri (2009) que o departamento responsável pela gestão da cooperação internacional da instituição deve ser claramente definido, bem como suas atribuições, competências e responsabilidades. Esta designação é parte fundamental para o sucesso do empreendimento. Neste quesito, entende-se que existe tal indicação, conforme UFSC (2015b).

Os dados coletados apresentaram um significativo número de convênios firmados e um processo de formalização que acompanha em grande parte o modelo proposto por Rudzki (1998). A pesquisa também demonstrou que existe uma sequência clara de tarefas a serem realizadas no que diz respeito ao processo de formalização dos acordos de cooperação internacional. Com efeito, o fluxograma construído explicitou tal rotina.

Como proposta para futuros trabalhos, sugere-se um aprofundamento do estudo com entrevistas com os gestores e participantes do processo, a fim de detalhar características e complementar informações não disponíveis no momento atual, que poderão identificar a necessidade ajustes e melhorias, além do estudo dos resultados dos convênios firmados.

Os desafios propostos pelas novas demandas de internacionalização da educação superior são muitos, tais como as barreiras culturais, de linguagem, além das diferenças entre os sistemas de ensino. Assim, pois, torna-se imprescindível a implantação de um plano de internacionalização, o qual deve envolver toda a comunidade universitária. Todas as partes devem estar sensibilizadas e comprometidas, de modo a agir com o mesmo objetivo, propiciando melhores resultados. Outrossim, os gestores envolvidos diretamente devem estar devidamente capacitados e constantemente atualizados a respeito das linguagens que as demais instituições do mundo estão adotando (STALLIVIERI, 2009).

Desta forma, acredita-se que a Universidade Federal de Santa Catarina, por intermédio da sua Secretaria de Relações Internacionais, está buscando a sua inserção nesse cenário de internacionalização. A realização de uma pesquisa mais aprofundada poderá identificar se ela está no caminho correto, ou se deve realizar ajustes na condução desse processo. O que fica posto é que já existe um trabalho estabelecido. E que a internacionalização, uma vez que permite que a educação superior enfrente os desafios propostos pela globalização por meio da produção, difusão e aplicação do conhecimento, é uma tendência a ser seguida pelas instituições que pretendem estar entre as mais conceituadas de sua área.

\section{REFERÊNCIAS}

ABC. Agência Brasileira de Cooperação. Disponível em: <http://www.abc.gov.br/>. Acesso em: 29 jul. 2015.

ANDIFES. Programa de Expansão, Excelência e internacionalização das universidades federais. Brasília, 2012. Disponível em <http://www.andifes.org.br/wp-content/files_flutter/1360930928PEEXIU.pdf>. Acesso em 25 abr. 2016.

BARRAL, Welber. Metodologia da pesquisa jurídica. 2. ed. Florianópolis: Fundação Boiteux, 2003. BEELEN, Jos. Left to Their Own Devices: The Role and Skills of Academics in Partnerships for the Future. In: JOOSTE, Nico; de WIT, Han; HELETA, Savo (Ed.). Higher Education: Partnerships for the Future. Porto Elizabeth: Unit for 
Higher Education Internationalisation in the Developing World, 2015. p. 47-61.

BERLINCK, Manoel Tosta. O método científico nos primórdios da Universidade: o caso de Andreas Vesalius de Bruxelas.Revista Ensino Superior, Campinas, v. 11, n. 123, p. 51-64, 24 out. 2013. Disponível em: <https://www.revistaensinosuperior.gr.unicamp.br/edicoes/ed11_outubro2013/HISTORIA.pdf>. Acesso em: 15 jun. 2015.

CAPES. Cooperação Internacional. Disponível em: <http://www.capes.gov.br/cooperacao-internacional>. Acesso em: 21 jul. 2015.

CNPQ. CNPq. Brasília, 2015a. Disponível em: <http://www.cnpq.br/>. Acesso em: 21 jul. 2015.

0 programa - Ciência sem fronteiras. Brasília, 2015b. Disponível em:

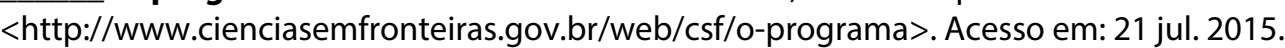

DAL-SOTO, Fábio et al. Processos de Internacionalização de Instituições de Ensino Superior (IES) do Consórcio das Universidades Comunitárias Gaúchas (COMUNG). In: ENCONTRO DA ANPAD, 37., 2013, Rio de Janeiro. Anais... Rio de Janeiro: ANPAD, 2013. p. 1-16. Disponível em:

<http://www.anpad.org.br/admin/pdf/2013_EnANPAD_ESO1323.pdf>. Acesso em: 15 jun. 2015.

DE WIT, Hans. Partnerships for the Future: Trends, Challenges and Opportunities. In: JOOSTE, Nico; de WIT, Hans; HELETA, Savo (Ed.). Higher Education: Partnerships for the Future. Porto Elizabeth: Unit for Higher Education Internationalisation in the Developing World, 2015. p. 47-61.

DUFFIELD, Stacy; OLSON, Alan; KERZMAN, Renee. Crossing Borders, Breaking Boundaries: Collaboration Among Higher Education Institutions. Innov High Educ, [s.I.], v. 38, n. 3, p.237-250, 27 set. 2012. Disponível em: <http://link.springer.com/article/10.1007/s10755-012-9238-8>. Acesso em: 15 abr. 2016.

FORPROEX - FORUM DE PRÓ-REITORES DE EXTENSÃO DAS INSTITUIÇÕES DE EDUCAÇÃO DE ENSINO SUPERIOR PÚBLICAS BRASILEIRAS COMISSÃO DE RELAÇÕES INTERNACIONAIS. Programa de internacionalização da Extensão Universitária (Minuta da Proposta). Palmas (TO), 06 a 09 nov. 2013. Disponível em <http://wp.ufpel.edu.br/prec/files/2013/11/inter_ext.pdf>. Acesso em 25 abr. 2016.

GACEL, Jocelyne; ÁVILA, Ricardo. Universidades latinoamericanas frente al reto de la internacionalización. Casa del Tiempo,Cidade do México, v. 1, n. 9, p. 2-8, jul. 2008. Disponível em: <http://www.difusioncultural.uam.mx/casadeltiempo/09_iv_jul_2008/casa_del_tiempo_elV_num09_02_08.pdf>. Acesso em: 15 jun. 2015.

GODOY, Arilda S. Introdução a pesquisa qualitativa e suas possibilidades. Revistas de Administração, v. 35, n. 2, p. 57-63, mar./abr. 1995.

HAGENMEIER, Cornelius. Ensuring Equality in Higher Education Partnerships Involving Unequal Universities in Divergent Contexts. In: JOOSTE, Nico; de WIT, Han; HELETA, Savo (Ed.). Higher Education: Partnerships for the Future. Porto Elizabeth: Unit for Higher Education Internationalisation in the Developing World, 2015. p. 41-46.

HUDZIK, John K. Strategic Institutional Partnerships and Comprehensive Internationalisation. In: JOOSTE, Nico; WIT, de Han; HELETA, Savo (Ed.). Higher Education: Partnerships for the Future. Porto Elizabeth: Unit for Higher Education Internationalisation in the Developing World, 2015. p. 23-39.

JOOSTE, Nico. Higher Education Partnerships for the Future: A View From the South. In: JOOSTE, Nico; de WIT, Hans; HELETA, Savo (Ed.). Higher Education: Partnerships for the Future. Porto Elizabeth: Unit for Higher Education Internationalisation in the Developing World, 2015. p. 11-21.

JULIATTO, Dante Luiz et al. Implantação de modelo de gestão baseada em processos em uma universidade federal. In: SIMPÓSIO DE ENGENHARIA DE PRODUÇÃO, 19., 2012, Bauru. Anais... Bauru: UNESP, 2012.

KNIGHT, Jane. The changing landscape of higher education internationalisation: for better or worse? Perspectives: Policy and Practice in Higher Education, Manchester, v. 17, n. 3, p. 84-90, Feb. 2013. KNIGHT, Jane. International Universities: Misunderstandings and Emerging Models? Journal Of Studies In International Education, [s.I.], v. 19, n. 2, p. 107-121, 23 Feb. 2015. SAGE Publications. DOI:

$10.1177 / 1028315315572899$. 
LEITE, Denise; GENRO, Maria Elly Herz. Avaliação e internacionalização da Educação Superior: Quo vadis América Latina? Avaliação, Campinas; Sorocaba, v. 17, n. 3, p. 763-785, nov. 2012.

MOROSINI, Marília Costa. Estado do conhecimento sobre internacionalização da educação superior: Conceitos e práticas. Educar, Curitiba, v. 28, p. 107-124, jul./dez. 2006.

. Internacionalização na produção de conhecimento em IES brasileiras: cooperação internacional tradicional e cooperação internacional horizontal. Educação em Revista, Belo Horizonte, v. 27, n. 1, p. 93-112, abr. 2011.

OLIVEIRA, Djalma de Pinho Rebouças de. Administração de processos: conceitos, metodologia, práticas. São Paulo, SP: Atlas, 2006.

ORTIZ, Jaime. International Business Education in a Global Environment: A Conceptual Approach. International Education Journal, Adelaide, v. 5, n. 2, p.255-265, jul. 2004. Disponível em:

<http://files.eric.ed.gov/fulltext/EJ903853.pdf>. Acesso em: 15 abr. 2016.

RUDZKI, Romuald Edward John. The strategic management of internationalization: towards a model of theoiy and practice. 1998. 331 f. Tese (Doutorado) - Curso de Filosofia na Faculdade de Educação, University Of Newcastle upon Tyne, Reino Unido, 1998.

SILVA, Darly Henriques da. Cooperação internacional em ciência e tecnologia: oportunidades e riscos. Revista Brasileira de Política Internacional, Brasília, v. 50, n. 1, p.5-28, jun. 2007. Disponível em: <http://www.scielo.br/scielo.php?script=sci_arttext\&pid=S0034-73292007000100001\&lng=en\&nrm=iso >. Acesso em: 15 jun. 2015.

SOUZA, Eduardo Pinheiro de; FLEURY, Maria Tereza Leme. Estratégias e Competências para a Internacionalização de Instituições de Ensino Superior do Brasil. EnANPAD, 33., 2009, São Paulo. Trabalhos Apresentados. Rio de Janeiro: ANPAD, 2009. Disponível em: <http://www.anpad.org.br/admin/pdf/ESO3200.pdf>. Acesso em: 15 jun. 2015.

STALLIVIERI, Luciane. As dinâmicas de uma nova linguagem intercultural na mobilidade acadêmica internacional. 2009. 234 f. Tese (Doutorado) - Curso de Doutorado em Línguas Modernas, Universidad del Salvador, Buenos Aires, 2009.

TEICHLER, Ulrich. Mutual Recognition and Credit Transfer in Europe: Experiences and Problems. Journal Of Studies In International Education, [s. I.], v. 7, n. 4, p. 312-341, winter 2003.

UNESCO. Educação superior: reforma, mudança e internacionalização. Anais. Brasília: UNESCO Brasil, SESU, 2003. $208 \mathrm{p}$.

UNIÃO EUROPEIA. Processo de Bolonha: estabelecimento do Espaço Europeu do Ensino Superior. Disponível em: $<$ http://europa.eu/legislation_summaries/education_training_youth/lifelong_learning/c11088_pt.htm>. Acesso em: 20 jun. 2015.

UNIVERSIDADE FEDERAL DE SANTA CATARINA (UFSC). Estatuto. Florianópolis, 2015a. Disponível em: https://repositorio.ufsc.br/bitstream/handle/123456789/99561/Estatuto2013.pdf?sequence=1. Acesso em: 22 jul. 2015.

SINTER. Florianópolis, 2015b. Disponível em: <http://sinter.ufsc.br>. Acesso em: 20 jul. 2015.

UNIVERSIDADE DE SÃO PAULO (USP). Política de internacionalização do ensino e da pesquisa. São Paulo, 2009. Disponível em <http://www.eefe.usp.br/arquivos/internacional/pol-internacionalizacao-eefe.pdf> Acesso em 25 abr. 2016.

VEIGA, R. Internacionalização das instituições de ensino superior em Portugal: proposta de metodologia para a construção de indicador do grau de internacionalização. 2012. Dissertação (Mestrado em Negócios Internacionais) Escola Superior de Tecnologia e Gestão (ESTG) do Instituto Politécnico de Leiria, Leiria, 2012.

VERGARA, Sylvia Constant. Projetos e relatórios de pesquisa em administração. São Paulo: Atlas, 1997. 